\title{
Childhood friendships and the clustering of adverse circumstances in adulthood - a longitudinal study of a Stockholm cohort
}

\author{
Ylva B Almquist \\ Centre for Health Equity Studies, Stockholm University/Karolinska Institutet \\ yba@chess.su.se \\ Lars Brännström \\ Swedish Institute for Social Research, Stockholm University
}

(Received June 2012 Revised June 2013)

doi: $10.14301 /$ Ilcs.2013.3.2

\section{Abstract}

Friendships constitute a central feature of childhood, yet little is known about the developmental significance extending beyond childhood and adolescence. Based on longitudinal data for more than 14,000 individuals born in Stockholm in 1953, this study investigates the association between childhood friendships and groupings of adult outcomes, here conceptualised as conditions related to education, employment, economic hardship and health. Children's outcome profiles as adults were identified by means of latent class analysis. Multinomial logistic regression analysis was used to analyse whether childhood friendships predicted adult outcome profiles net of observed family background characteristics. The results indicated that children who lacked leisure time friends and a best friend in the school class, had increased risks of ending up in the more adverse clusters as adults, whereas the opposite association was found for those who reported being solitary. The effect of childhood friendships was rather consistent across both single and multiple problems, suggesting that the disadvantages of being without friends in childhood may not accumulate over the life course to any large extent. Generally, the findings were the same for males and females. The results were not explained by various family-related circumstances during upbringing. It is concluded that childhood friendships are important for adverse circumstances in adulthood, for both genders. As far as the long-lasting effects of children's friendships involve varying access to social support, school-based interventions should compensate for the scarcity of support following the lack of childhood friends.

Keywords: Childhood, friendship, living conditions, life course, cohort, latent class analysis

\section{Introduction}

It is widely acknowledged that friendships constitute a central feature of childhood, closely related to children's development. Taking their starting-point in a life-course perspective, scholars have argued that research into children's friendships needs to highlight the developmental significance extending beyond childhood and adolescence (Almquist, 2011a; Hartup \& Stevens, 1997, 1999). The aim of the present study is therefore to examine the links between childhood friendships and adult outcomes. However, rather than focusing on various adult outcomes analysed in isolation, the present study adopts a personoriented approach where the emphasis is put on the pattern of outcomes as a whole.

\section{The importance of childhood friendships}

While the interest in children's friendships has grown rapidly over the last decade or two (Berndt, 2004), the measurement issues surrounding this field of research remain difficult to solve. Most 
would however, agree to the definition of friendship as a bilateral construct, since it emerges from the interaction between two individuals who have reciprocated positive feelings for one another (Bukowski \& Hoza, 1989). For this reason, researchers have typically focused on pairs, or dyads, of children as the unit of analysis. These friendship dyads have commonly been identified through the use of peer nomination procedures, where children are asked to select their best friends or the classmates they like the most (Erdley, Nangle, Newman, \& Carpenter, 2001). Assessments of friendships have, however, also been based on more lenient criteria, such as self-reports of the number of friendships (Gifford-Smith \& Brownell, 2003; van der Horst \& Coffé, 2012). Although the significance of quantitative aspects of friendship has been stressed (i.e. having friends), more qualitative measures (e.g. identity of friends and friendship quality) are being studied to an increasing extent (Hartup \& Stevens, 1997). In the present study, three indicators of childhood friendships will be examined: hanging out with friends during leisure time, experiencing solitude, and having a best friend in the school class. While the two former are self-assessed, the latter is based on peer nominations. These three indicators are assumed to capture different, but perhaps similarly important, dimensions of friendship. For example, best friend reflects the situation in the school class; a context which is known to constitute one of the most significant arenas for peer interaction (Cairns \& Cairns, 1994; Hartup, 1984). It also captures the deep structure of friendship, i.e. reciprocity (Hartup \& Stevens, 1997). Hanging out with schoolmates outside school is a measure of companionship (Heaney \& Israel, 2008) and could provide important opportunities to maintain and 'nurture' friendships obtained at school (Flora \& Segrin, 1998). Finally, solitude is likely to reflect a more qualitative aspect of friendlessness, namely the subjective feeling of being without a close friend (Inderbitzen-Pisaruk, Clark, \& Solano, 1992).

The scientific literature has identified a number of important provisions that are obtained through friendships (Furman \& Robbins, 1985). For example, children's friendships provide affection (experiencing strong and positive ties); intimacy (sharing secrets and personal aspects); and a sense of reliable alliance (being loyal and sharing resources). Friendships also reflect inclusion (feeling a sense of belonging and acceptance). Other provisions are instrumental aid (getting help if needed); nurturance (feeling competent and needed); enhancement of worth (feeling proud and valued); and companionship (sharing activities). Considering this, it is not surprising that previous research has found friendships to be strongly correlated to a variety of indicators of adjustment (e.g. Zettergren, Bergman, \& Wångby, 2006). For example, children with friends have been found to be more socially out-going and pro-social; have higher self-worth and self-esteem; and manage difficult transitions more smoothly (Bagwell, Newcomb, \& Bukowski, 1998; Berndt, 1996; Berndt, Hawkins, \& Jiao, 1999; Gest, Graham-Bermann, \& Hartup, 2001). Children without friends, on the other hand, have been found to be more shy, timid, withdrawn, sensitive and unsuccessful at solving conflicts (Parker \& Seal, 1996; Rubin, Bukowski, \& Parker, 1998; Shantz \& Shantz, 1985).

There are some longitudinal studies that have examined various aspects of friendship as predictors of subsequent developmental outcomes. However, most of these studies have had short follow-up periods and included rather small sample sizes. The results indicate, for example, that the lack of a (best) friend predicts depression (Erdley et al., 2001); suicidal thoughts (Bearman \& Moody, 2004); internalising and externalising problems (Ladd \& Troop-Gordon, 2003); emotional distress (Wentzel, Caldwell, \& Barry, 2004); and academic achievement (Wentzel \& Caldwell, 1997). Since relevant longitudinal data materials with a lengthy follow up are rare, studies focusing on whether the effects of children's friendships could last into young adulthood and beyond are not as numerous. Some do nevertheless exist: one study by Bagwell and colleagues (1998) indicated that those who were friendless in 5th grade were more likely to have psychopathological symptoms at age 23 . This pattern was also demonstrated when these individuals were additionally followed-up at age 28 (Bagwell, Schmidt, Newcomb, \& Bukowski, 2001). Another study (Almquist, 2011a) showed that having fewer friendships in childhood (age 8-12) was linked to an increased risk of poor self-reported health in mid-life (age 45-52).

In sum, the overall conclusion that may be drawn from research into children's friendships is that children who have less favourable experiences with friends also have increased risks of 
developmental problems and, moreover, these risks do not appear to be confined to childhood and adolescence.

\section{The clustering of adverse circumstances in adulthood}

Given the fact that certain aspects of children's friendships, such as being without a friend, have shown persistent effects across a wide range of developmental outcomes in childhood and adolescence, it is reasonable to expect a similar consistency in the associations with adult outcomes. Moreover, it is well-known that difficulties in adulthood may go hand in hand (Bask, 2011; Bäckman \& Nilsson, 2011; Fritzell, Gähler, \& Nermo, 2007; Fritzell \& Lundberg, 2000). It could thus be the case that a small group of individuals have a general susceptibility toward a wide range of adversities and thereby make up for a large proportion of the associations across outcomes. Consequently, it may be misguided to study a catalogue of adult outcomes in isolation.

One way of dealing with this issue is to instead examine the clustering of outcomes. Here, some parallels may be drawn to the person-oriented approach which originates from the field of developmental psychology (Bergman \& Trost, 2006; Eye \& Bogat, 2006). This approach, among other things, puts emphasis on the fact that it is the outcome pattern as a whole that carries the information rather than the parts regarded separately (Bergman, Magnusson, \& El-Khouri, 2003; Bergman \& Trost, 2006). Through the use of cluster analytical methods, it is possible to create outcome profiles where individuals are being categorised according to how similar or dissimilar they are to one another: for some individuals, one type of problem in adulthood may dominate whereas specific combinations or accumulation of problems may apply to other groups. In the present study, the aim is thus to investigate the potential influences of childhood friendships on the grouping of various outcomes in adult life. The outcomes are chosen to reflect a broad picture of adverse circumstances in adulthood and, as such, they include health-related, economic and social indicators. A similar strategy has been applied in another study using the same data material (Almquist \& Brännström, 2012). Based on information about educational level, social assistance benefits, unemployment as well as mental and behavioural disorders, they distinguished four clusters of which one represented 'average' individuals, two reflected single problems, and the last comprised the most problem-burdened individuals.

Due to the scarcity of studies focusing on the long-lasting effects of childhood friendships, little is known about the pathways linking friendship to adult outcomes. Some inspiration may be drawn from research into the importance of family-related conditions as childhood precursors of future life chances, where it has been maintained that the individual's access to resources determines the level of opportunity at various stages across the life course. The lack of resources at one stage may result in limited resources at the next stage, thus bringing about a concatenation of disadvantages (Elder, 1998). As previously discussed, friendships involve important provisions. The lack of these provisions in childhood may impinge on circumstances (and hence the access to resources) at subsequent stages of life: first, through psychosocial mechanisms such as expectations, emotions, and ambitions. This is assumed to further influence the individual's educational choices, health-related behaviours, membership of networks, and coping strategies, which could ultimately have impacts on adult outcomes (cf. Almquist, 2011a; Almquist, 2011b; Östberg \& Modin, 2007) in terms of e.g. educational career, income, labour market attachment and health.

\section{Gender differences}

Children tend to choose friends who are similar to themselves, particularly in terms of gender (McPherson, Smith-Lovin, \& Cook, 2001; Shrum, Cheek, \& Hunter, 1988). Gender is thus an underlying segregating principle for children's social interaction. A vast amount of research has found that females' friendships provide higher levels of closeness, affection, nurturance, trust and security (for a review, see Rose \& Rudolph, 2006). It is therefore reasonable to assume that the lack of friendships is more disadvantageous for females' subsequent life chances. This has, however, not yet been fully confirmed in empirical studies.

\section{Study aim}

Based on a longitudinal cohort study of children born in Stockholm in 1953, the overall aim of the study is to examine the importance of childhood friendships for the clustering of adverse circumstances in adulthood. Indicators of childhood 
friendship are: leisure time friends, solitude, and best friend. The adult circumstances, based on which various outcome profiles will be determined, include educational level, social assistance benefits, unemployment, and mental and behavioural disorders. Furthermore, various possible confounders reflecting social conditions related to the family will be examined (e.g. parental social class, income and education as well as family type, number of siblings and parental mental health problems). The role of gender for the studied associations will be investigated as well.

The following research questions will be investigated:

1) Are childhood friendships, in terms of a) leisure time friends, b) solitude, and c) best friend, associated with the clustering of adverse circumstances in adulthood?

2) Does the effect of childhood friendships vary across outcome profiles?

3 ) Is the association between childhood friendships and the clustering of adverse circumstances in adulthood confounded by social conditions during upbringing?

4) Are there any gender differences in any of the studied associations?

Based on previous research and theory, it is tentatively hypothesised that those who lack friends in childhood (in terms of each of the three friendship indicators) have increased risks of experiencing adverse circumstances in adulthood in general, and multiple difficulties in particular. Moreover, the strength of these associations is expected to be more pronounced among females compared to males.

\section{Methods}

The data material used is the Stockholm Birth Cohort Study (SBC), which was created in $2004 / 2005$ by a probability matching of two longitudinal data sets: The Stockholm Metropolitan Study (SMS) and The Swedish Work and Mortality Data Base (WMD). The SMS cohort was initially defined as all children born in 1953 and living in the Stockholm metropolitan area in 1963 ( $n=15,117)$. All data was de-identified in 1986. In 2004-2005, the SMS was linked by a probability matching to the WMD, which is a temporary, population-based and anonymous database of Swedish residents who were born before 1985 and alive in 1980 and/or 1990. Of the original 15,117 individuals, approximately $95 \% \quad(n=14,294)$ were positively matched and thereby included in the SBC (for a detailed description of the matching procedure, see Stenberg \& Vågerö, 2005). Ethical permission for the SBC has been obtained from the Stockholm Regional Ethics Committee (No 739-03-629).

\section{Variables}

The present study uses four types of adult circumstances to calculate the outcome profiles: educational level social assistance benefits, unemployment, and mental and behavioural disorders. Concerning childhood friendships, three indicators were included: leisure time friends, solitude and best friend. Variables reflecting parental social class, parental income, parental education, family type, number of siblings, and parental mental health problems were included as controls (Table 1).

Information about educational level, social assistance benefits and unemployment in adulthood was derived from a Swedish registry database called Longitudinal Integration Database for Health Insurance and Labour Market Studies (LISA). To begin with, information about educational level in 2007 was based on the Swedish Educational Terminology (SUN), consisting of seven categories: pre-primary education; primary and lower secondary education, less than 9 years; primary and lower secondary education, 9 (or 10) years; upper secondary education; post-secondary education, less than two years; post-secondary education, two years or longer; and post-graduate education. In the present study, this variable was transformed into three categories: compulsory; upper secondary; and university. Secondly, based on the registered income from social assistance benefits during the period 1992-2007, dichotomised measures for each year were calculated (receiving benefits in 1992, yes or no; receiving benefits in 1993, yes or no; and so forth). The sum of years was subsequently recoded into the following categories: 0 years; $1-2$ years; and 3 or more years. Thirdly, yearly information about the number of days in full-time unemployment was derived for the period 1992-2007. This variable was re-coded and collapsed in the same way as for social assistance benefits, thus indicating varying degrees of unemployment experience. 
Table 1. Descriptive statistics for all study variables $(n=10,694)$

\begin{tabular}{|c|c|c|c|c|c|}
\hline \multirow[t]{3}{*}{ Variable } & \multirow{3}{*}{$\begin{array}{l}\text { Year/time } \\
\text { period }\end{array}$} & \multicolumn{4}{|c|}{ Distribution } \\
\hline & & \multicolumn{2}{|c|}{ Males $(n=5,022)$} & \multicolumn{2}{|c|}{ Females $(n=5,672)$} \\
\hline & & $\mathrm{n}$ & $\%$ & $\mathrm{n}$ & $\%$ \\
\hline Leisure time friends & 1966 & & & & \\
\hline Yes & & 4,850 & 96.6 & 5,481 & 96.6 \\
\hline No & & 172 & 3.4 & 191 & 3.4 \\
\hline Solitude & 1966 & & & & \\
\hline No & & 4,810 & 95.8 & 5,347 & 94.3 \\
\hline Yes & & 212 & 4.2 & 325 & 5.7 \\
\hline Best friend & 1966 & & & & \\
\hline Yes & & 4,625 & 92.1 & 4,953 & 87.3 \\
\hline No & & 397 & 7.9 & 719 & 12.7 \\
\hline Educational level & 2007 & & & & \\
\hline Compulsory & & 857 & 17.1 & 652 & 11.5 \\
\hline Upper secondary & & 2,200 & 43.8 & 2,525 & 44.5 \\
\hline University & & 1,965 & 39.1 & 2,495 & 44.0 \\
\hline Unemployment & 1992-2007 & & & & \\
\hline 0 years & & 3,438 & 68.5 & 3,724 & 65.7 \\
\hline $1-2$ years & & 678 & 13.5 & 850 & 15.0 \\
\hline 3 or more years & & 906 & 18.0 & 1,098 & 19.4 \\
\hline Social assistance benefits & 1992-2007 & & & & \\
\hline 0 years & & 4,159 & 82.8 & 4,428 & 78.1 \\
\hline $1-2$ years & & 472 & 9.4 & 660 & 11.6 \\
\hline 3 or more years & & 391 & 7.8 & 584 & 10.3 \\
\hline Mental and behavioural disorders & 1992-2007 & & & & \\
\hline 0 admissions & & 4,740 & 94.4 & 5,408 & 95.4 \\
\hline 1-2 admissions & & 156 & 3.1 & 153 & 2.7 \\
\hline 3 or more admissions & & 126 & 2.5 & 111 & 2.0 \\
\hline Parental social class & 1963 & & & & \\
\hline Upper/upper middle & & 841 & 16.8 & 910 & 16.0 \\
\hline Non-manual, officials & & 1,775 & 35.3 & 1,997 & 35.2 \\
\hline Non-manual, entrepreneurs & & 378 & 7.5 & 465 & 8.2 \\
\hline Manual, skilled & & 1,121 & 22.3 & 1,277 & 22.5 \\
\hline Manual, unskilled & & 788 & 15.7 & 902 & 15.9 \\
\hline Other & & 119 & 2.4 & 121 & 2.1 \\
\hline Parental income (thousands of SEK) & 1964 & Mean $=1$ & & Mear & \\
\hline Parental education & 1960 & & & & \\
\hline No graduate & & 3,520 & 70.1 & 4,001 & 70.5 \\
\hline One graduate & & 1,005 & 20.0 & 1,128 & 19.9 \\
\hline Two or more graduates & & 306 & 6.1 & 314 & 5.5 \\
\hline No information & & 191 & 3.8 & 229 & 4.0 \\
\hline Family type & 1964 & & & & \\
\hline Two-parent household & & 4,586 & 91.3 & 5,122 & 90.3 \\
\hline Other & & 436 & 8.7 & 549 & 9.7 \\
\hline Number of siblings & 1964 & Range $=$ & & Rang & \\
\hline Parental mental health problems & 1953-1965 & & & & \\
\hline No & & 4,832 & 96.2 & 5,455 & 96.2 \\
\hline Yes & & 190 & 3.8 & 217 & 3.8 \\
\hline
\end{tabular}


Finally, information about mental and behavioural disorders was derived from the Hospital discharge register. This measure was based on the number of discharges from Swedish hospitals (in-patient care) due to mental and behavioural disorders, during the period 1992-2007. Using the 9th Revision (for the period 1992-1996) and the 10th Revision (for the period 1997-2007) of the International Classification of Diseases (ICD), diagnoses in the ICD 9 chapter 'Mental disorders' (290-319) and the ICD 10 chapter 'Mental and behavioural disorders' (F00-F99) were coded as mental and behavioural disorders (including e.g. depression, anxiety and substance abuse). The variable was collapsed into three categories: 0 admissions; 1-2 admissions; and 3 or more admissions.

The three measures of childhood friendships leisure time friends, solitude and best friend - were based on information from the School Study of 1966. All school classes in Stockholm were included in the School Study, with the exception of classes of children with learning disabilities. The measure of leisure time friends was derived from the question: "How often do you spend your leisure time with some of your school mates?' The response options were: 'Every day'; 'A few times a week'; 'Once a week'; 'Seldom'; and 'Never'. Individuals who had responded 'Never' were put into one category (3\%), whereas the rest formed another category. The measure of solitude was based on the question: "With whom do you spend most of your time?" The response options were: 'Mostly with boys'; 'Mostly with girls'; 'Mostly with a group of boys and girls'; 'Mostly with adults'; and 'I am mostly on my own'. Those who answered 'I am mostly on my own' were categorised as being solitary (5\%), whereas the remaining individuals were put into another category. Lastly, based on a peer nomination procedure, the measurement of best friend could be derived. All students in each school class were asked: "Who are your three best friends in class?" Individuals who did not receive any nominations from their classmates were assumed to lack a best friend $(10 \%)$, whereas the rest were categorised as having at least one best friend. The choice of distinguishing relatively extreme categories was made, in order to more clearly discriminate individuals who could be considered to have friendship problems, from those who did not. The results from a correlation analysis showed positive but weak correlations between the three measures (leisure time friends and solitude: $r=0.14$; leisure time friends and best friend: $r=0.05$; and solitude and best friend: $r=0.06$ ).

Six types of family-related circumstances during upbringing were included as control variables in the analysis (for the distribution of these variables, see Table 1. Parental social class (1963) was based on precoded occupational data concerning the head of the household (in most cases the father). Parental income (1964) was measured through the mean of the combined earned income of both parents. Information about parental education (1960) was based on the total number of household members who graduated from secondary school or equivalent. Concerning family type (1964), two categories were distinguished: children who were recorded as living in a two-parent household (biological parents or reconstituted families) and those who lived in any other type of families (single-parent household, foster parents or widow/widower). Furthermore, a continuous measure of the number of siblings (1964) was included. With regard to parental mental health problems (1953-1965), it had originally been divided into three categories: psychiatric problems or depressed; receiving psychiatric treatment; and committed to an institution for care. All these categories were, in this study, used as indicators of parental mental health problems. The six indicators of family-related circumstances were weakly correlated, also with the indicators of friendship. Most correlations were lower than 0.20 and many below 0.10 , with the following exceptions (ranging between 0.20 and 0.40 ): parental income and parental social class; parental education and parental social class; and family type and parental income.

\section{Data analysis}

Based on the information about circumstances in adulthood, 'outcome profiles' were generated to identify similarities between individuals in the present study. Here, latent class analysis was applied, using Mplus 6.1. The basic notion underlying latent class analysis is that there are unobserved relationships among observed variables (Hagenaars \& McCutcheon, 2002). The number of clusters was determined through different indicators of model fit (see Table 2). For example, the Bayesian Information Criterion (BIC) and the Akaike Information Criterion (AIC) can be used to assess the relative goodness of fit of different models, where lower values indicate better fit (Kuha, 2004). In the present study, BIC was lowest for the three-cluster solution, whereas the five-cluster solution had the lowest AIC. The four-cluster solution 
had the second lowest values in both instances. A further analysis showed that the five-cluster model had better scores for entropy (reflecting the quality of the classification, where a value of 0 reflects randomness and a value of 1 corresponds to a perfect classification). Moreover, the models with four and five clusters respectively did not have problems with correlated bivariate residuals. The choice between the models was further based on a Vuong-Lo-Mendell-
Rubin likelihood ratio test (Henson, Reise, \& Kim, 2007) which showed that the four-cluster solution had significantly better model fit compared to the threecluster solution, whereas the five-cluster solution did not fit the data better than the four-cluster solution. The model with four clusters was therefore preferred. Performing a gender-specific analysis yielded virtually the same four-cluster solution (data not presented).

Table 2. Latent class analysis: model fit statistics $(n=10,694)$

\begin{tabular}{|c|c|c|c|c|c|}
\hline $\begin{array}{l}\text { Number of } \\
\text { classes/clusters }\end{array}$ & AIC & BIC & $\begin{array}{l}\text { Entropy/Quality } \\
\text { of classification }\end{array}$ & $\begin{array}{l}\text { Uncorrelated } \\
\text { bivariate } \\
\text { residuals }\end{array}$ & $\begin{array}{l}\text { Likelihood } \\
\text { ratio test }^{a}\end{array}$ \\
\hline 1 & 58428.371 & 58486.591 & 1.000 & No & - \\
\hline 2 & 56408.556 & 56532.272 & 0.734 & No & $p<0.000$ \\
\hline 3 & 56287.673 & 56476.886 & 0.589 & No & $p<0.000$ \\
\hline $4^{b}$ & 56250.974 & 56505.684 & 0.631 & Yes & $p<0.000$ \\
\hline 5 & 56250.284 & 56570.491 & 0.658 & Yes & $p=0.304$ \\
\hline \multicolumn{6}{|l|}{ Notes. } \\
\hline $\begin{array}{l}\text { BIC = Bayesian Infor } \\
\text { AIC=Akaike Informa } \\
{ }^{a} \text { Vuong-Lo-Mendel } \\
{ }^{b} \text { Preferred model }\end{array}$ & $\begin{array}{l}\text { mation Criteri } \\
\text { tion Criterion } \\
\text {-Rubin likeliho }\end{array}$ & atio test & & & \\
\hline
\end{tabular}

The next step was to analyse the association between childhood friendships and adverse circumstances in adulthood. Since the outcome was nominal (i.e. non-ordered response categories), multinomial regression analysis was used, producing relative risk ratios (RRR). The RRRs were obtained by exponentiating the multinomial logit coefficients. Three models were generated, of which the first demonstrates the effects of each friendship indicator separately, adjusted for gender. Here, the results from the interaction analysis were also included. Each interaction term was calculated by multiplying a friendship variable with the gender variable, of which both had a binary coding (zero and one). The new variable could thus also have the possible values of zero and one. The second model incorporates the effects of all three indicators of childhood friendships simultaneously, as well as gender. Finally, the third model controls for the various family-related circumstances (social class, income and education of parents, as well as family type, number of siblings and parental mental health problems). The results from the multinomial regression analysis are displayed in Table 3.

\section{Study sample}

The analyses performed in the present study are based on individuals with information about all study variables. Of the original SBC sample $(n=14,294), 10,694$ individuals were thereby included (to some extent positively selected in terms of childhood conditions, data not presented).

\section{Results}

In Figure 1, the four-cluster solution produced by the latent class analysis is demonstrated, using a plot of the estimated probabilities. The labeling of the clusters is based on the level of the probabilities. The first cluster contains $68 \%$ of the individuals and includes those with comparably More education (E). The second cluster is characterised by relatively Less education (e), containing $13 \%$ of the sample. In the third cluster, which contains $13 \%$ of the individuals, More unemployment $(U)$ is evident. Finally, the fourth cluster, containing $6 \%$ of the sample, is more problem-burdened compared to the others, with comparably Less education, more social assistance benefits, more unemployment, and more mental and behavioural disorders (eSUM). 
Figure 1. Description of the outcome profiles; estimated probabilities derived using Mplus, number of cases and relative cluster size within brackets $(n=10,694)$

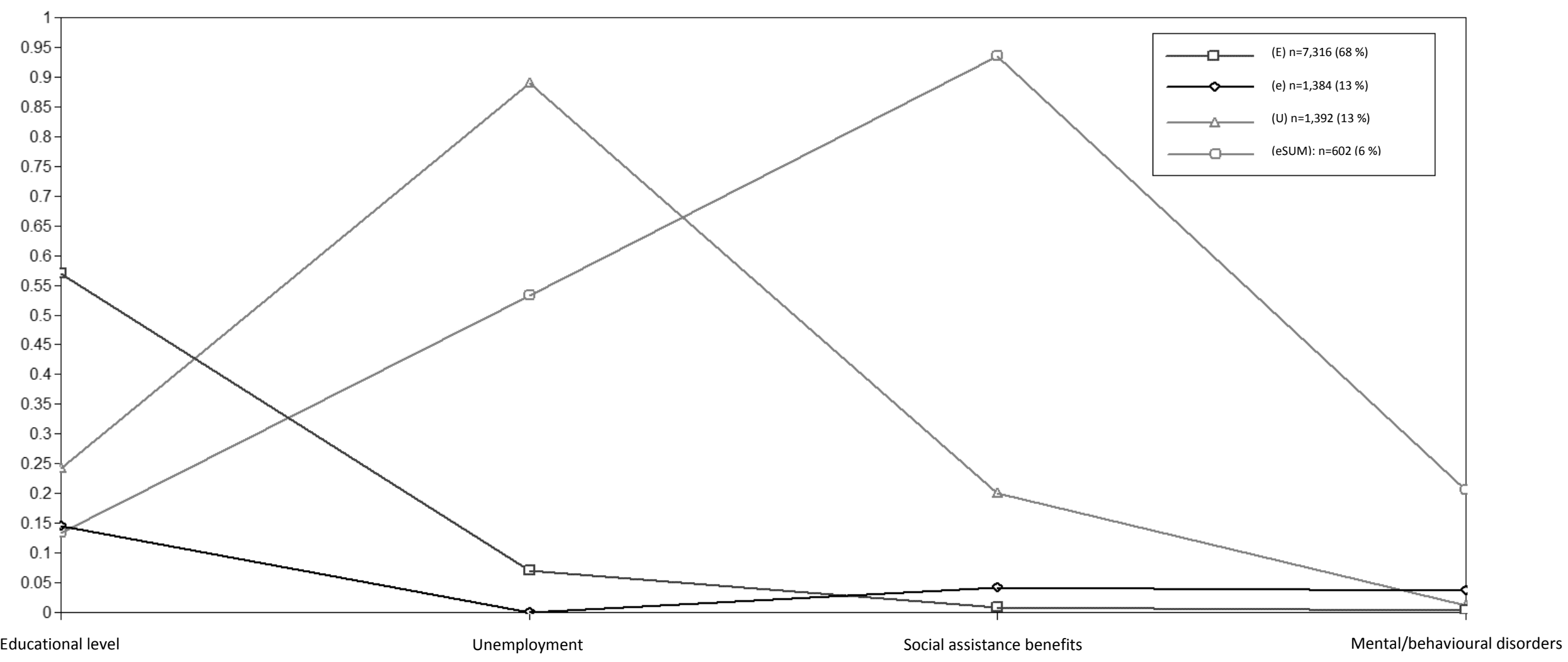

Key

E: More education; e: Less education; U: More unemployment; eSUM: Less education, more social assistance benefits, more unemployment, and more mental and behavioural disorders 
Table 3 presents the association between childhood friendships and adverse circumstances in adulthood. The gender-adjusted results from Model 1 indicate, firstly, that those who lack leisure time friends have a $37 \%$ higher risk of ending up in the cluster characterised by Less education (e) rather than in the More education cluster (E). These individuals also have an increased risk (68\% and $89 \%$, respectively) of being found in the cluster characterised by More unemployment (U) as well as in the most problem-burdened cluster (eSUM). In the lower part of the table, the results from the interaction analysis are presented. There are no statistically significant gender differences in the association between leisure time friends and adult circumstances. In Model 2, where the three indicators of childhood friendships are included simultaneously, the estimates remain largely unchanged. No statistically significant interaction effects between the indicators of friendship were found here (data not presented). Model 3 controls for the various family-related circumstances, reducing the risk: e.g. the risk for individuals without leisure time friends to end up in the Less education (e) cluster decreases from 1.37 to 1.26 and is no longer statistically significant.

When it comes to solitude, Model 1 shows that those who have reported that they are solitary have decreased risks of ending up in the clusters characterised by Less education (e), More unemployment $(U)$ and More unemployment, more social assistance benefits, more mental and behavioural disorders, and less education (eSUM). Thus, contrary to what was expected, solitude shows a negative association with the clustering of adverse circumstances in adulthood. These results are however not statistically significant. The interaction analysis presented in the lower part of the table indicates that females who experience solitude in childhood have decreased risks to end up in the Less education (e) cluster and increased risks of ending up in the More unemployment (U) cluster compared to males. The estimates in the mutually adjusted column (Model 2) become slightly increased compared to the gender-adjusted results (Model 1 ). When the control variables are added to Model 3, the strength of the association between solitude and adult circumstances is marginally reduced.

Concerning the third indicator of childhood friendships, the gender-adjusted results (Model 1 ) suggest that those who lack a best friend have an increased risk of adverse circumstances in adulthood. For example, individuals who did not receive any nominations for best friend from their classmates have a $51 \%$ increased risk of later ending up in the cluster characterised by Less education (e), rather than in the More education cluster. Higher risks are also found for the two remaining clusters: $51 \%$ for the More unemployment cluster (U) and $85 \%$ for the most problem-burdened cluster (eSUM). No statistically significant interaction between best friend and gender is found. When the effects of all three friendship measures are included simultaneously (Model 2), only marginal changes occur. Model 3, which incorporates the effect of the control variables, shows that a limited part of the association between having a best friend and adult circumstances is accounted for by family-related circumstances.

Finally, although not displayed in Table 3 , it should be noted that there were some 'crude' effects of gender on adverse circumstances in adulthood. More specifically, while no gender differences in the risk of ending up in the Less education (e) cluster were demonstrated, females had a $16 \%$ higher risk of being found in the More unemployment cluster ( $U$ ) and a $29 \%$ higher risk to end up in the most problem-burdened cluster (eSUM). These results are also largely reflected in Model 2, although these estimates are adjusted for the three friendship indicators. 
Table 3. The association between childhood friendships and the clustering of adverse circumstances in adulthood.

Leisure time friends

Yes (ref.)

No

Solitude

No (ref.)

Yes

Best friend

Yes (ref.)

No

Gender

Males (ref.)

Females

Leisure time friends * gender

Solitude * gender

Best friend * gender

\section{Results from multinomial regression analysis $(n=10,694)$}

$\mathbf{U}$

\section{eSUM}

\begin{tabular}{|c|c|c|c|c|c|c|c|c|}
\hline Model $1^{a}$ & Model $2^{b}$ & Model $3^{c}$ & Model $1^{a}$ & Model $2^{b}$ & Model $3^{c}$ & Model $1^{a}$ & Model $2^{b}$ & Model $3^{c}$ \\
\hline $\operatorname{RRR}(95 \% \mathrm{Cl})$ & $\operatorname{RRR}(95 \% \mathrm{Cl})$ & $\operatorname{RRR}(95 \% \mathrm{Cl})$ & $\operatorname{RRR}(95 \% \mathrm{Cl})$ & $\operatorname{RRR}(95 \% \mathrm{Cl})$ & $\operatorname{RRR}(95 \% \mathrm{Cl})$ & $\operatorname{RRR}(95 \% \mathrm{Cl})$ & $\operatorname{RRR}(95 \% \mathrm{Cl})$ & $\operatorname{RRR}(95 \% \mathrm{Cl})$ \\
\hline 1.00 & 1.00 & 1.00 & 1.00 & 1.00 & 1.00 & 1.00 & 1.00 & 1.00 \\
\hline 1.37 (1.01-1.86) & $1.37(1.01-1.87)$ & $1.26(0.92-1.72)$ & $1.68(1.27-2.23)$ & $1.67(1.25-2.23)$ & $1.56(1.16-2.08)$ & $1.89(1.29-2.78)$ & $1.90(1.29-2.80)$ & $1.68(1.13-2.49)$ \\
\hline 1.00 & 1.00 & 1.00 & 1.00 & 1.00 & 1.00 & 1.00 & 1.00 & 1.00 \\
\hline $0.85(0.64-1.12)$ & $0.79(0.60-1.04)$ & $0.82(0.62-1.09)$ & $0.92(0.71-1.20)$ & $0.84(0.64-1.09)$ & $0.86(0.66-1.13)$ & $0.81(0.54-1.21)$ & $0.70(0.46-1.06)$ & $0.74(0.49-1.12)$ \\
\hline 1.00 & 1.00 & 1.00 & 1.00 & 1.00 & 1.00 & 1.00 & 1.00 & 1.00 \\
\hline \multirow[t]{3}{*}{$1.51(1.27-1.80)$} & $1.51(1.27-1.81)$ & $1.46(1.22-1.75)$ & $1.51(1.27-1.80)$ & $1.50(1.25-1.78)$ & $1.45(1.21-1.73)$ & $1.85(1.46-2.33)$ & $1.83(1.45-2.32)$ & $1.74(1.37-2.22)$ \\
\hline & 1.00 & 1.00 & & 1.00 & 1.00 & & 1.00 & 1.00 \\
\hline & $1.07(0.95-1.20)$ & $1.06(0.94-1.19)$ & & $1.14(1.02-1.28)$ & $1.13(1.01-1.27)$ & & $1.25(1.06-1.48)$ & $1.15(1.05-1.48)$ \\
\hline n.s. & & & n.s. & & & n.s. & & \\
\hline$p<0.01$ & & & $p<0.05$ & & & n.s. & & \\
\hline n.s. & & & n.s. & & & n.s. & & \\
\hline
\end{tabular}

Notes.

More education ( $E$ ) is the reference group.

${ }^{a}$ Adjusted for gender

${ }^{\mathrm{b}}$ Adjusted for gender + mutual adjustment for friendship indicators

${ }^{c}$ Adjusted for gender, parental social class, parental education, parental income, family type, number of siblings, and parental mental health problems + mutual adjustment for friendship indicators

RRR=Relative risk ratio

E: More education; e: Less education; U: More unemployment; eSUM: Less education, more social assistance benefits, more unemployment, and more mental and behavioural disorders 


\section{Discussion}

\section{Childhood friendships as a predictor of adverse circumstances in adulthood}

The aim of the present study was to examine the association between various indicators of childhood friendships and the clustering of adverse circumstances in adulthood. The results suggested that such links do exist: children who did not hang out with school friends during leisure time and did not had a best friend in their school class, had increased risks of adversities as adults. This is consistent with previous studies identifying harmful long-term effects among those who were without friends in childhood (Almquist, 2011a; Bagwell et al., 1998; Bagwell et al., 2001). Moreover, the association between childhood friendships and adult circumstances was not fully accounted for by any of the family-related circumstances included in the study (e.g. the socioeconomic status and mental health of the parents, as well as family type and number of siblings).

The explanations for the link between childhood friendships and the clustering of adversities in adulthood may reside in the functions of friendships, where social support previously has been identified as a key aspect (Heaney \& Israel, 2008). Four types of social support, linked to various types of provisions, are commonly differentiated: emotional (love, trust and caring), instrumental (aid and services), informational (advice, suggestions and information), and appraisal (constructive feedback and affirmation). It is reasonable to assume that individuals who lack friends in childhood have a lower level of support, which in turn could make them less equipped to deal with various choices and events occurring across the life course (e.g. getting an education, entering the labour market, and adopting healthy behaviours).

While some have argued that social support is beneficial only for individuals under stress and, as such, 'buffers' the adverse effects of stressful events, others maintain that social support is linked to the individual's outcomes irrespective of whether a stressor is present (Cohen \& Wills, 1985). The present study did not attempt to separate between buffering effects and main effects of childhood friendships. In other words, although a main effect of social support on adult outcomes was observed, this does not rule out childhood friendships as a potentially buffering factor.

\section{The case of solitude}

All indicators of childhood friendships did not display the same association to adult circumstances. On the contrary of what was expected, individuals who reported being solitary in childhood seemed to have lower risks of ending up in outcome profiles characterised by high levels of adverse outcomes. Thus, it appears as if solitude is protective against later problems. This should however be interpreted with the low correlations between the indicators of childhood friendships in mind: solitude seems to be composed primarily of aspects not related to hanging out with classmates during leisure time and having a best friend in the school class. Rather, it could be the case that children who report being solitary still have high levels of social support originating from other people (e.g. friends outside school, family and siblings) as well as other important resources, which in turn could counterbalance the negative effects of experiencing solitude. A sensitivity analysis (data not presented) showed, for example, that those who reported being solitary had higher average marks compared to those who did not experience solitude (whereas the opposite pattern was shown for the other two indicators of childhood friendships). Thus, this group of children may still have the abilities required to end up in more advantageous outcome profiles later in life.

\section{Relative importance of friendship indicators}

The results revealed independent effects of all three indicators of childhood friendships on adverse circumstances later in life. Again, this could be ascribed to the low correlations between these indicators. Having a best friend in the school class seems to involve a process that is different from hanging out with classmates during leisure time and also different from being solitary. For example, having a best friend is likely to reflect reciprocity, i.e. mutual liking and acceptance, to a greater extent. As such, it is reasonable to expect that emotional support is the primary type of provision gained by these individuals. Spending time with classmates outside of the school is, on the other hand, strongly related to the presence of companionship, which is another function commonly mentioned in friendship research. Companionship involves, for example, the sharing 
of activities during leisure time (Heaney \& Israel, 2008). This may imply joint membership in organisations or networks (e.g. youth or sports clubs), which in turn could further boost the provision of various types of social support. Lastly, solitude was initially assumed to reflect loneliness since it entailed being mostly on one's own. Loneliness has previously been described as a multidimensional phenomenon that encompasses the individual's experience of an unpleasant lack of relationships (de Jong Giervald, 1998). Young people are believed to be especially vulnerable to loneliness due to the increased importance of friendship during this period in life (InderbitzenPisaruk et al., 1992). However, as previously mentioned, children who reported being solitary still enjoyed academic success, something which provides resources that are perhaps even more salient for adult living conditions than social support.

\section{Accumulation of problems over the life course}

Based on the indicators of adverse circumstances in adulthood, the latent class analysis revealed four outcome profiles: the first two reflected higher and lower education, respectively. The third was characterised by higher levels of unemployment whereas the fourth reflected adversities in all four arenas: less education, more social assistance benefits, more unemployment, and more mental and behavioural disorders. The corresponding cluster solution has been found in a previous study of children's status position in the peer group as a predictor of subsequent living conditions (Almquist \& Brännström, 2012). Additionally, in that study, low peer status showed the strongest link to the most problem-burdened cluster, suggesting that adverse circumstances may accumulate over time (cf. DiPrete \& Eirich, 2006). In the present study, contrary to what was initially expected, there were no stronger effects of childhood friendships on profiles characterised by multiple problems: with the cluster characterised by comparably higher levels of education as the reference, the risks were rather evenly distributed across the other profiles. This could indicate that the negative effects of being without friends in childhood may not accumulate over the life course to any large extent.

\section{Gender differences}

In the cohort studied here, males had slightly lower levels of unemployment and social assistance benefits as well as a higher number of hospitalisations due to mental and behavioural disorders, whereas females were somewhat more educated. However, the cluster analysis revealed the same outcome profiles for both genders (data not presented), which suggests that males and females are similar to one another when it comes to the ' $m i x$ ' of adverse problems in adulthood. The regression analysis largely confirmed this, although females had a higher risk of ending up in the cluster characterised by higher levels of unemployment, as well as the most problem-burdened cluster compared to males. Concerning the association between childhood friendships and the clustering of adverse circumstances in adulthood, no gender differences were found, with the exception of solitude, where solitary females had a decreased risk of being found in the cluster characterised by less education, and an increased risk of ending up in the cluster with higher levels of unemployment. In sum, however, males and females appear to be more similar than different when it comes to the issues examined in the present study.

\section{The use of a person-oriented approach}

In the present study, a person-oriented approach was favoured over a variable-oriented approach. The person-oriented approach focuses on the pattern of outcomes as a whole, targeting the ways in which individuals are similar or dissimilar to one another in terms of e.g. adverse living conditions. A major advantage of applying this approach was that the researchers could empirically identify different combinations of adverse living conditions. Another advantage was that the personoriented approach did not assume that linear associations exist between the variables or for all individuals. In order to highlight these important differences between the person-oriented approach and the variable-oriented approach, the analysis in the present study was also performed by using the latter strategy (Appendix 1). First, a summary measure of adverse living conditions was created ( 0 problems; 1 problem; 2 problems; 3-4 problems). At first glance, the distribution of this variable roughly corresponded to the percentages of individuals in the various clusters (Table A). However, a more scattered picture emerges when cross-comparing the two distributions (Table B). The greatest 
consistency is shown for the More education (E) cluster as well as the most problem-burdened cluster (eSUM) which is mainly represented by individuals who also were identified as having multiple problems in the summary measure (2-4 problems). The remaining clusters correspond considerably less to the summary measure. The association between childhood friendships and adverse circumstances in adulthood (using the summary measure) was subsequently analysed using ordinal regression analysis (Table C). The results indicate that individuals who lack of friendships in childhood have more problems as adults. However, in comparison to the previous analyses, this approach masks the combinations of problems that exist in the data, and (more or less incorrectly) assumes that the effect of the predictor is linear on the outcome. The conclusion drawn here is that the person-oriented approach, through its emphasis on outcome patterns, may extend the knowledge previously established by more traditional research.

\section{Strengths and limitations}

With rich information on childhood friendships and adult circumstances, the Stockholm Birth Cohort study provided an excellent opportunity to investigate these matters in detail. There are, however, some limitations that need to be recognised. First of all, the indicators of childhood friendships were predominantly school-based; the measure of best friend referred to classmates, whereas the question regarding leisure time friends referred to schoolmates. Given that the question about solitude was posed in a battery of schoolrelated items, it is possible that the respondents gave their answers as primarily based on conditions in school. Since the school constitutes a central arena for the establishment and maintenance of friendships, it is fully reasonable to focus on schoolbased friendships. It should nevertheless be acknowledged that children may also have supportive friendships outside of school. Furthermore, the three chosen indicators were mostly concerned with the quantitative aspects of friendships. Previous research has highlighted the importance of also taking into account the quality of friendships as well as who the friends are (Hartup \& Stevens, 1997). For example, having a friend may not be as beneficial for subsequent outcomes if the relationship is characterised by conflict and distrust, or if the friend has adopted adverse behaviours. These dark sides of friendships could offset the positive effects to some extent. A second issue has to do with causality. The present study controlled for several factors reflecting social conditions during childhood (i.e. parental social class, income, education and mental health problems as well as family type and number of siblings). This did not lead to any substantial changes in the results. However, other circumstances, which could not be taken into account here, may be equally or even more important, such as the child's own health status. Moreover, no mechanisms were investigated. It is plausible that factors such as the individual's educational choices and entrance into the labour market may be of relevance (Bäckman \& Nilsson, 2011).

Finally, it should be pointed out that the results of the present study are based on a cohort of Stockholm children born in 1953. The clustering of living conditions should be viewed in the light of its context: Sweden is generally considered a generous welfare state with a well-developed 'safety net'. Hence, it could be argued that the very existence of clustering of adult adversity, diverges from the idea of a welfare state which aims to compensate for the unequal distribution of opportunity across groups of people. Regardless of the content and structure of the clusters, however, it is reasonable to expect that the association between childhood friendships and adult outcomes would look similar in other geographical and cultural contexts. More research is needed to verify this.

\section{Concluding remarks}

Childhood friendships matter for the risk of adverse circumstances in adulthood, among males and females alike. It is suggested that the provisions gained through childhood friendships have longlasting effects on individual outcomes. Friendship is based on mutual liking and, therefore, it would be impracticable to try to enforce such relationships among children. Rather, school-based intervention programmes should aim at finding ways to compensate for the lack of social support among those who are without friends in childhood. 


\section{Acknowledgements}

The creation and maintenance of the Stockholm Birth Cohort Data Base is a collaboration between the Centre for Health Equity Studies (CHESS) and the Swedish Institute for Social Research (SOFI), financed by the Swedish Research Council. Sten-Åke Stenberg of SOFI prepared the original Metropolitan Data Base, Denny Vågerö of CHESS prepared the follow-up data, and Reidar Österman of CHESS organised the probability matching of the two data sets. The present study was financially supported by the Swedish Research Council for Health, Working Life and Welfare (grant number 2012-0201).

\section{References}

Almquist, Y. (2011a). Childhood friendships and adult health: findings from the Aberdeen Children of the 1950s Cohort study. European Journal of Public Health, doi:10.1093/eurpub/ckr1045.

Almquist, Y. (2011b). A class of origin: The school class as a social context and health disparities in a lifecourse perspective. Stockholm: Stockholm University.

Almquist, Y. B., \& Brännström, L. (2012). Childhood peer status and the clustering of adverse living conditions in adulthood. SOFI Working papers 1/2012. Stockholm: Stockholm University.

Bäckman, O., \& Nilsson, A. (2011). Pathways to social exclusion - a life-course study. European Sociological Review, 27, 107-123. Bagwell, C. L., Newcomb, A. F., \& Bukowski, W. M. (1998). Preadolescent friendship and peer rejection as predictors of adult adjustment. Child Development, 69, 140-153.

Bagwell, C. L., Schmidt, M. E., Newcomb, A. F., \& Bukowski, W. M. (2001). Friendship and peer rejection as predictors of adult adjustment. New Directions for Child and Adolescent Development, 91, 25-49.

Bask, M. (2011). Cumulative disadvantage and connections between welfare problems. Social Indicators Research, 103, 443-464.

Bearman, P. S., \& Moody, J. (2004). Suicide and friendships among American adolescents. American Journal of Public Health, 94, 89-95.

Bergman, L. R., Magnusson, D., \& El-Khouri, B. (2003). Studying individual development in an interindividual context. A person-oriented approach. London: Lawrence Erlbaum Associates.

Bergman, L. R., \& Trost, K. (2006). The person-oriented versus the variable-oriented approach: Are they complementary, opposites, or exploring different worlds? Merrill-Palmer Quarterly, 52, 601-632.

Berndt, T. J. (1996). Friendship quality affects adolescents' selfesteem and social behavior. In W. M. Bukowski, A. F. Newcomb \& W. W. Hartup (Eds.), The company they keep: Friendship during childhood and adolescence (pp. 346-365). New York: Cambridge University Press.

Berndt, T. J. (2004). Children's friendships: shifts over a half-century in perspectives on their development and their effects. Merrill-Palmer Quarterly, 50, 206-223.

Berndt, T. J., Hawkins, J. A., \& Jiao, Z. (1999). Influences of friends and friendships on adjustment to junior high school. Merrill-Palmer Quarterly, 45, 13-41.

Bukowski, W. M., \& Hoza, B. (1989). Popularity and friendship: Issues in theory, measurement, and outcome. In T. J. Berndt \& G. W. Ladd (Eds.), Peer relationships in child development (pp. 15-45). New York: Wiley.

Cairns, R. B., \& Cairns, B. D. (1994). Lifelines and risks. Cambridge: Cambridge University Press.

Cohen, S., \& Wills, T. A. (1985). Stress, social support, and the buffering hypothesis. Psychological Bulletin, 98, 310-357.

de Jong Giervald, J. (1998). A review of loneliness: concept and definitions, determinants and consequences. Reviews in Clinical Gerontology, 8, 73-30.

DiPrete, T. A., \& Eirich, G. M. (2006). Cumulative advantage as a mechanism for inequality: a review of theoretical and empirical developments. Annual Review of Sociology, 32, 271-297.

Elder, G. H. J. (1998). Life course as developmental theory. Child Development, 69, 1-12.

Erdley, C. A., Nangle, D. W., Newman, J. E., \& Carpenter, E. M. (2001). Children's friendship experiences and psychological adjustment: theory and research. In D. W. Nangle \& C. A. Erdley (Eds.), New directions for child and adolescent development: the role of friendship in psychological adjustment (pp. 5-23). San Francisco: Jossey-Bass.

Flora, J., \& Segrin, C. (1998). Joint leisure time in friend and romantic relationships: the role of activity type, social skills and positivity. Journal of Social and Personal Relationships, 15, 711-718.

Fritzell, J., Gähler, M., \& Nermo, M. (2007). Vad hände med 1990-talets stora förlorargrupper? Välfärd och ofärd under 2000-talet [What happened to the disadvantaged groups of the 1990s? Welfare and disadvantage during the first years of the new millennium]. Socialvetenskaplig tidskrift, 2-3, 110-133.

Fritzell, J., \& Lundberg, O. (2000). Ofärdens ackumulering och samvariation [The accumulation and covariation of illfare]. Delrapport från Kommittén Välfärdsbokslut [Interim report by the Welfare Commission]. SOU 2000:41. Stockholm: Fritzes. 
Furman, W., \& Robbins, P. (1985). What's the point? Issues in the selection of treatment objectives. In B. H. Schneider, K. H. Rubin \& J. E. Ledingham (Eds.), Children's peer relations: Issues in assessment and intervention(Insert page numbers here please). New York: Springer-Verlag.

Gest, S. D., Graham-Bermann, S. A., \& Hartup, W. W. (2001). Peer experience: Common and unique features of number of friendships, social network centrality, and sociometric status. Social Development, 10 , 23-40.

Gifford-Smith, M. E., \& Brownell, C. A. (2003). Childhood peer relationships: social acceptance, friendships, and peer networks. Journal of School Psychology, 41, 235-284.

Hagenaars, J. A., \& McCutcheon, A. L. (2002). Applied latent class analysis. New York: Cambridge University Press.

Hartup, W. W. (1984). The peer context in middle childhood. In W. A. Collins (Ed.), Development during middle childhood (pp. 240-282). Washington D. C.: National Academy Press.

Hartup, W. W., \& Stevens, N. (1997). Friendships and adaption in the life course. Psychological Bulletin, 121, 355-370.

Hartup, W. W., \& Stevens, N. (1999). Friendships and adaptation across the life span. Current Directions in Psychological Science, 8, 76-79.

Heaney, C. A., \& Israel, B. A. (2008). Social network and social support. In K. Glanz, B. K. Rimer \& K. Viswanath (Eds.), Health behavior and health education: theory, research, and practice (Insert page numbers here please). San Francisco: Jossey-Bass.

Henson, J. M., Reise, S. P., \& Kim, K. H. (2007). Detecting mixtures from structural model differences using latent mixture modeling: A comparison of relative model fit statistics. Structural Equation Modeling: A Multidisciplinary Journal, 14, 202-226.

Inderbitzen-Pisaruk, H., Clark, M. L., \& Solano, C. H. (1992). Correlates of loneliness in midadolescence. Journal of Youth and Adolescence, 21, 151-167.

Kuha, J. (2004). AIC and BIC. Comparisons of assumptions and performance. Sociological Methods Research, $33,188-229$.

Ladd, G. W., \& Troop-Gordon, W. (2003). The role of chronic peer difficulties in the development of children's psychological adjustment problems. Child Development, 74, 1344-1367.

McPherson, M., Smith-Lovin, L., \& Cook, J. M. (2001). Birds of a feather: homophily in social networks. Annual Review of Sociology, 27, 415-444.

Östberg, V., \& Modin, B. (2007). Status relations in school and their relevance for health in a life course perspective: Findings from the Aberdeen children of the 1950's cohort study. Social Science \& Medicine, 66, 835-848.

Parker, J. G., \& Seal, J. (1996). Forming, losing, renewing, and replacing friendships: Applying temporal parameters to the assessment of children's friendship experiences. Child Development, 67, 22482268.

Rose, A. J., \& Rudolph, K. D. (2006). A review of sex differences in peer relationship processes: Potential trade-offs for the emotional and behavioral development of girls and boys. Psychological Bulletin, $132,98-131$.

Rubin, K. H., Bukowski, W., \& Parker, J. G. (1998). Peer interactions, relationships, and groups. In W. Darnon \& N. Eisenberg (Eds.), Handbook of child psychology (pp. 619-700). New York: John Wiley.

Shantz, C. U., \& Shantz, D. W. (1985). Conflict between children: Social cognitive and sociometric correlates. In M. W. Berkowitz (Ed.), Peer conflict and psychological growth (pp. 3-21). San Francisco: JosseyBass.

Shrum, W., Cheek, N. H. J., \& Hunter, S. M. (1988). Friendship in school: gender and racial homophily. Sociology of Education, 61, 227-239.

Stenberg, S.-A., \& Vågerö, D. (2005). Cohort Profile: The Stockholm birth cohort of 1953. International Journal of Epidemiology, 35, 546-548.

van der Horst, M., \& Coffé, H. (2012). How friendship network characteristics influence subjective well-being. Social Indicators Research, 107, 509-529.

Wentzel, K. R., \& Caldwell, K. A. (1997). Friendships, peer acceptance, and group membership: Relations to academic achievement in middle school. Child Development, 68, 1198-1209.

Wentzel, K. R., Caldwell, K. A., \& Barry, C. N. (2004). Friendships in middle school: Influences on motivation and school adjustment. Journal of Educational Psychology, 96, 195-203.

Zettergren, P., Bergman, L. R., \& Wångby, M. (2006). Girls' stable peer status and their adulthood adjustment: A longitudinal study from age 10 to age 43. International Journal of Behavioral Development, 30, 315-325. 


\section{Appendix 1}

Table A. Description of a summary measure* of problems in adulthood $(n=10,694)$

Distribution

\begin{tabular}{lrrrr} 
& \multicolumn{2}{c}{ Males $(\mathbf{n = 5 , 0 2 2 )}$} & \multicolumn{2}{c}{ Females $(\mathbf{n = 5 , 6 7 2 )}$} \\
\cline { 2 - 5 } & $\mathrm{n}$ & $\%$ & $\mathrm{n}$ & $\%$ \\
\cline { 2 - 5 } 0 problems & 2,642 & 52.6 & 2,812 & 49.6 \\
1 problem & 1,463 & 29.1 & 1,839 & 32.4 \\
2 problems & 654 & 13.0 & 815 & 14.4 \\
3-4 problems & 263 & 5.2 & 206 & 3.6 \\
\hline
\end{tabular}

* A 'problem' is defined in the following way:

Educational level: Less than secondary education in 2007; Social assistance benefits: Receiving social assistance benefits at some point during the period 1992-2007; Unemployment: Being unemployed at some point during the period 1992-2007; Mental and behavioural disorders: At least one admission from the hospital during the period 1992-2007

Table B. Comparison between the cluster solution and the summary measure $(n=10,694)$

\begin{tabular}{lrrrr} 
& E & e & U & eSUM \\
\hline 0 problems & 5,454 & 0 & 0 & 0 \\
1 problem & 2,378 & 273 & 532 & 120 \\
2 problems & 53 & 471 & 556 & 389 \\
$3-4$ problems & 0 & 69 & 86 & 314 \\
\hline
\end{tabular}

E: More education; U: More unemployment; E: Less education; eSUM: Less education, more social assistance benefits, more unemployment, and more mental and behavioural disorder

\section{Table $\mathrm{C}$. The association between childhood friendships and the clustering of adverse circumstances in adulthood. Results from ordinal regression analysis $(n=10,694)$}

\begin{tabular}{|c|c|c|c|}
\hline & \multicolumn{3}{|c|}{ Problems in adulthood (high score $=$ more problems) } \\
\hline & Model $1^{a}$ & Model $2^{b}$ & Model $3^{c}$ \\
\hline & OR $(95 \% \mathrm{Cl})$ & OR $(95 \% \mathrm{Cl})$ & OR $(95 \% \mathrm{Cl})$ \\
\hline \multicolumn{4}{|c|}{ Leisure time friends } \\
\hline Yes (ref.) & 1.00 & 1.00 & 1.00 \\
\hline No & $1.64(1.35-1.99)$ & $1.62(1.33-1.98)$ & $1.54(1.26-1.87)$ \\
\hline \multicolumn{4}{|l|}{ Solitude } \\
\hline No (ref.) & 1.00 & 1.00 & 1.00 \\
\hline Yes & $0.92(0.78-1.08)$ & $0.84(0.71-0.99)$ & $0.86(0.73-1.01)$ \\
\hline \multicolumn{4}{|l|}{ Best friend } \\
\hline Yes (ref.) & 1.00 & 1.00 & 1.00 \\
\hline No & $1.62(1.35-1.70)$ & $1.51(1.34-1.69)$ & $1.45(1.29-1.63)$ \\
\hline \multicolumn{4}{|l|}{ Gender } \\
\hline Males (ref.) & & 1.00 & 1.00 \\
\hline Females & & $1.06(0.99-1.14)$ & $1.04(0.97-1.12)$ \\
\hline
\end{tabular}

\footnotetext{
${ }^{a}$ Adjusted for gender

${ }^{b}$ Adjusted for gender + mutual adjustment for friendship indicators

${ }^{c}$ Adjusted for gender, parental social class, parental education, parental income, family type, number of siblings, and parental mental health problems + mutual adjustment for friendship indicators $\mathrm{OR}=$ Odds ratio
} 